\title{
Multiple Cutaneous Metastases \\ from Esophageal Adenocarcinoma
}

\section{Rohit Adyanthaya}

Published online: 7 May 2009

(C) Humana Press Inc. 2009

\section{Erratum to: Journal of Gastrointestinal Cancer} DOI 10.1007/s12029-009-9059-x

The original version of this article unfortunately contained a mistake. The first sentence of the abstract should read as: Cutaneous metastases from internal malignancies are very uncommon.

The online version of the original article can be found at http://dx.doi. org/10.1007/s12029-009-9059-x.

R. Adyanthaya $(\bowtie)$

Stony Brook University Hospital,

Stony Brook, NY 11794-8223, USA

e-mail: rohiteyedoctor@gmail.com 